\title{
Congenital hyperinsulinemic hypoglycemia: Review of the Indian scenario
}

\author{
Kochar IS, Ramachandran $\mathrm{S}^{*}$ and Sethi A \\ Indraprashta Apollo Hospital, New Delhi, India
}

\begin{abstract}
Congenital Hyperinsulinemic hypoglycemia (CHI) is a rare genetic disorder resulting severe hypoglycemia secondary to excessive insulin release from the pancreatic cells. Its early diagnosis is imperative to prevent irreversible brain damage by hypoglycemia. Genetic testing and 18-F-DOPA scan help to confirm the diagnosis.

We report the first heterozygous, paternally inherited $\mathrm{ABCC} 8$ missense mutation with focal pancreatic lesion from India and a review of the cases of $\mathrm{CHI}$ reported from India.
\end{abstract}

\section{Introduction}

Congenital Hyperinsulinemic hypoglycemia (CHI) is a rare genetic disorder resulting severe hypoglycemia secondary to excessive insulin release from the pancreatic cells. It is the most common etiology for infantile persistent hypoglycemia [1]. It is one of the most serious causes of neonatal hypoglycemia and can cause irreversible brain damage if not treated on time and adequately.

It has an estimated prevalence of 1 in 50000 and almost 1 in 25000 to 1 in 3000 in countries with consanguineous marriage [2]. The mutations in $\mathrm{ABBC} 8$ and $\mathrm{KCNJ} 11$ are the most commonly found mutations, however several other mutations have been reported.

$\mathrm{CHI}$ can manifest as either focal due to adenomatous islet cell or diffuse lesions secondary to diffuse islet cell hyperplasia [3].

The outcome in the patient primarily depends upon the kind of lesion as the focal lesions benefit from local pancreatectomy whereas the diffuse lesions require extensive pancreatectomy resulting in diabetes in a lot of children in later life [4].

We report a case of $\mathrm{CHI}$ with an $\mathrm{ABCC} 8$ gene mutations and a detailed review of the cases reported from India and the gene mutations prevalent.

\section{Case report}

This $2.7 \mathrm{~kg}$ male baby was born at term to non-consanguineous parents by normal vaginal delivery. He was exclusively breast-fed and had no complaints for the first three days of life. On day 4 of life the child was excessively lethargic for which was taken to a hospital, where he was detected to have blood sugar of $40 \mathrm{mg} / \mathrm{dl}$. He was given glucose containing intravenous fluids and sent home thereafter.

On day 6 of life the baby had seizures and was taken to the emergency where he was diagnosed to have hypoglycemia without any ketonuria. His blood sugars were closely monitored, and dextrose was added to the breast feeds, however the baby continued to have several episodes of hypoglycemia and was referred to our hospital.
The critical blood sample taken at a time of hypoglycemia revealed C-peptide $2.72 \mathrm{ng} / \mathrm{ml}$, blood sugar $22 \mathrm{mg} / \mathrm{dl}$, serum insulin $13.3 \mathrm{uU} / \mathrm{ml}$, with thyroid, cortisol and growth hormone being in normal range. $\mathrm{He}$ was started on oral diazoxide at $10 \mathrm{mg} / \mathrm{kg} /$ day and escalated to $15 \mathrm{mg} /$ $\mathrm{kg} /$ day for persisting hypoglycemia despite good compliance and regular blood sugar monitoring. The child was started on injectable subcutaneous octreotide at a dose of $2 \mathrm{mcg} / \mathrm{kg}$ and increased to $4 \mathrm{mcg} /$ $\mathrm{kg}$. Oral diazoxide was slowly tapered and stopped. A genetic study was done which showed that the child was heterozygous for the ABCC8 mutation missense variant., p.(Gly $111 \mathrm{Arg}$ ). The father heterozygous for $\mathrm{ABCC} 8$ variant and the mother did not has any genetic mutations. The child was maintaining his blood sugar with octreotide and dextrose supplemented breast feeds. Although several ABCC 8 mutations have been reported, a heterozygous, paternally inherited $\mathrm{ABCC} 8$ mutation missense variant, p.(Gly 111Arg) is the first case reported from India to the best of our knowledge.

An 18-Fluoro-DOPA scan detected an exophytic lesion $1.2 \mathrm{~cm}$ $\mathrm{x} 0.8 \mathrm{~cm}$ arising from the anterior part of the head of pancreas at the junction of the distal body and tail (Figure 1).

We followed up 18-F-Dopa with Ga exendin to diagnose and localize a focal lesion. It is a relatively new modality and confirmed the 18-F-Dopa findings in our case.

All the other Indian cases of ABCC8 mutation had diffuse involvement of the pancreas. This would be the first case of focal lesion at the pancreatic head with ABCC8 mutation in $\mathrm{CHI}$ to be reported from India.

*Correspondence to: Smita Ramachandran, Fellow Pediatric and Adolescent Endocrinology Indraprastha Apollo Hospital, New Delhi, India, Ph: 9818488818 ; E-mail: smita_rama25@yahoo.com

Key words: Congenital Hyperinsulinemic hypolglycemia (CHI), ABCC8, 18-F-DOPA, Indian cases, focal lesion

Received: September 07, 2018; Accepted: September 17, 2018; Published: September 21, 2018 


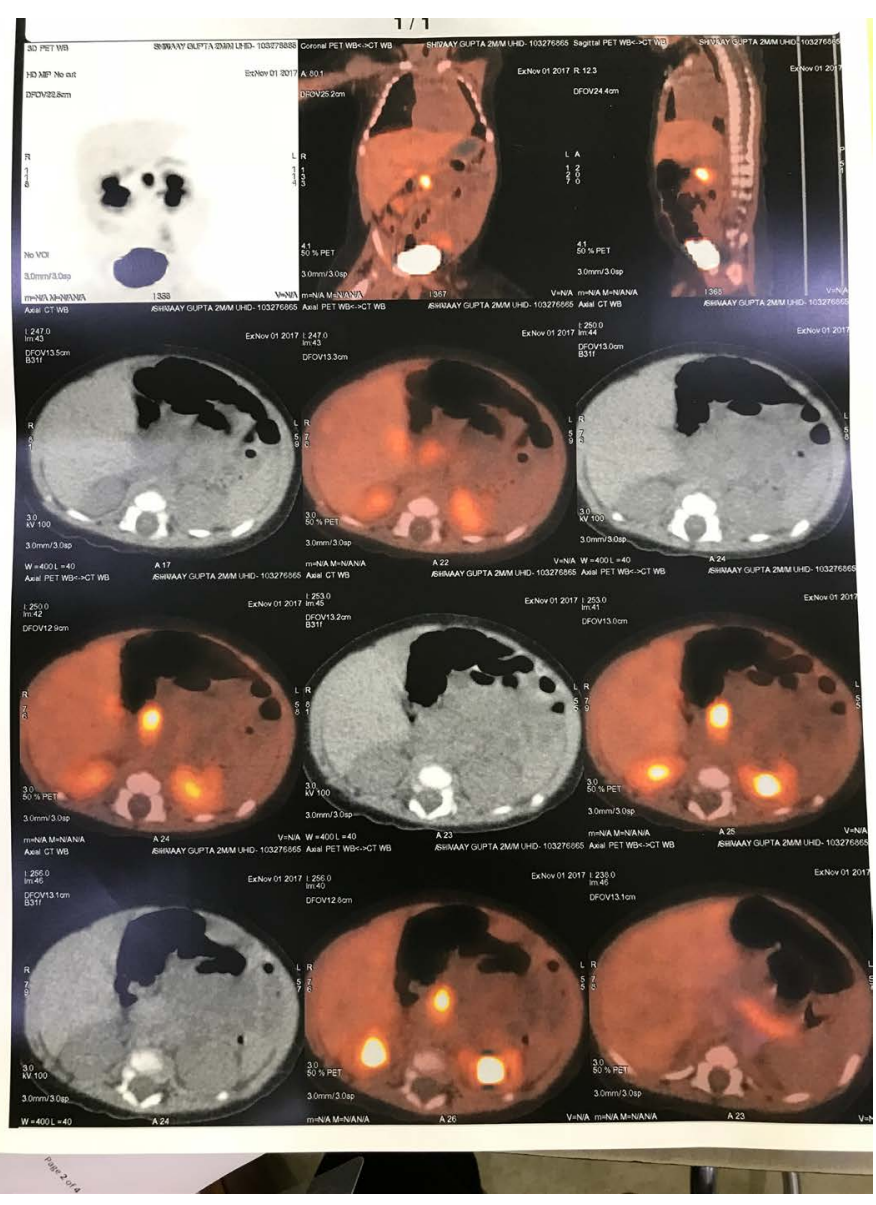

Figure 1. Congenital hyperinsulinemic hypoglycaemia

\section{Discussion}

$\mathrm{CHI}$ is a heterogeneous genetic disorder of abnormal insulin secretion characterized by hyperinsulinism, hypoketonemia, and hypofattyacidemia with severe and persistent hypoglycemia.

CHI can occur due to two major defects: channelopathies and metabolopathies. Channelopathies refer to defects in the pancreatic â-cell ATP-sensitive KATP channel that results in unregulated insulin secretion. Metabolopathies cause congenital hyperinsulinemic hypoglycemia either by altering the concentration of intracellular signaling molecules (such as ATP/ADP) or by accumulation of intermediary metabolites, triggering the insulin release.

The Na K-ATPase pump and the metabolic nutrient state regulate the insulin activity in the body. Genetic mutations render the pump functionally inactive, hence causing the patients to be unresponsive to diazoxide, while some mutations may cause the pump to be inactive but responsive to pharmacological interventions.

The mutations that increase the nutrient metabolism and increase the ATP/ADP ratio and in in turn increase the insulin secretion are the ones most responsive to diazoxide.

The most common mutations are the inactivating mutations of the $\beta$-cell ATP-sensitive $\mathrm{K}+$ channel genes ABCC8 (ATP- binding cassette subfamily C, member 8 ), which encodes for SUR1 (sulphonylurea receptor) and KCNJ11 (potassium inward rectifying channel, subfamily J, member 11), encoding Kir6.2 [5].
Genetic mutations have been identified in nine genes accounting for $\mathrm{CHI}$ resulting in either the diffuse or the focal form. Both autosomal dominant and recessive pattern have been demonstrated mostly in diffuse lesions resulting in the heterogeneity of presentation and severity. Focal ones are more sporadic.

It is hence very important to know the genetic mutations to predict the response to pharmacological interventions and their response in the affected children [6].

The most common mutations are the ABCC 8 and $\mathrm{KCNJ} 11$, located next to each other on chromosome $11 \mathrm{p}$. Till date there are 3 known Kirk6.2 and over 40 SURI mutations that have been identified [6].

Few other mutations have also been identified and can be useful in predicting the type of pancreatic involvements and responsiveness to diazoxide.

The other common mutations seen are:

- glucokinase (encoded by GCK)

- glutamate dehydrogenase (GDH; encoded by GLUD-1 [glutamate dehydrogenase]

- mitochondrial enzyme short-chain 3-hydroxyacyl-CoA dehydrogenase (SCHAD); encoded by HADH [hydroxyacylcoenzyme A dehydrogenase

The K- ATP-sensitive potassium channel hyperinsulinism (K-ATP$\mathrm{HI}$ ) form caused by mutations in ABCC8 and KCNJ11 on chromosome 11 , may cause autosomal recessive inheritance resulting in diffuse lesions and focal lesions due to loss of heterozygosity with paternal mutation. This type of resulting $\mathrm{CHI}$ is usually very severe and unresponsive to pharmacological treatment and requires pancreatectomy [7]. These babies are mostly large foe gestation due to fetal overgrowth due to excessive insulin.

The dominant K-ATP-HI is inherited as autosomal dominant, it is milder and responsive to diazoxide.

GDH-HI (glutamate dehydrogenase hyperinsulinism), caused by GLUD-1 mutation o chromosome $10 \mathrm{q}$ is autosomal dominant. It is associated with hyperammonemia and responsive to diazoxide. The hallmark of GDH-HI is recurrent episodes of fasting and postprandial hypoglycemia associated with persistent asymptomatic elevation of plasma ammonia levels. These babies are not born large for gestation and remain asymptomatic at birth, manifest symptoms by several months of age [8].

GK-HI (glucokinase hyperinsulinism), due to GCK mutation on chromosome 7 is autosomal dominant and has a variable presentation, but most of them respond to diazoxide. It is relatively rare and has a varied age of presentation and severity of symptoms. The islet cell morphology can also range from normal cells to enlarged islets [9].

SCHAD-HI (short-chain 3-hydroxyacyl-CoA dehydrogenase hyperinsulinis), by HADH mutation on chromosome 4 is inherited as autosomal recessive. It has an abnormal acyl-carnitine profile and is usually diazoxide responsive. The biochemical markers are increased insulin action; increased levels of plasma 3-hydroxybutyryl-carnitine and increased levels of 3-hydroxyglutarate in urine. Despite having a fatty acid oxidation defect, children do not have hepatic dysfunction, cardiomyopathy, or effects on skeletal muscle [10] (Table 1).

Cases of $\mathrm{CHI}$ have been reported in a few case series and reports from India, but less than 25 gene mutations have been detected in 
Table 1. Indian case of CHI

\begin{tabular}{|c|c|c|c|c|c|c|}
\hline S .no & Study & Year & Nos. & Place & Genes/zygosity & Imaging \\
\hline 1 & Kochar et al. & 2017 & 1 & Delhi & ABCC8/exon 3/Hetero & 18-F-DOPA PET \\
\hline 2 & Narayanan et al. [11] & 2016 & 16 & Chennai & 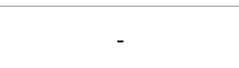 & $\begin{array}{c}\text { DOTONAC-5 } \\
\text { Gallium-1 }\end{array}$ \\
\hline 3 & Satapathy et al. [12] & 2016 & 1 & Delhi & HADH-exon 5 & - \\
\hline 4 & Rakesh kumar et al. [13] & 2015 & 1 & Delhi & - & DOTANOC \\
\hline 5 & Khawash et al. [14] & 2015 & 1 & Kolkatta & $\mathrm{ABCC} 8 /$ hetero & - \\
\hline 6 & Jahnavi et al. [15] & 2014 & 22 & Delhi & $\begin{array}{c}12 \text { ABCC8 detected } \\
\text { (2-exon1-hetero } \\
\text { 1-exon3-homo } \\
\text { 1-exon 5-hetero } \\
\text { 1-exon } 8 \\
\text { 1-exon } 12 \\
\text { 1-exon 16-homo } \\
\text { 1-exon } 21 \\
\text { 1-exon } 22 \\
\text { 1-IVS 30 } \\
\text { 1-exon 36-hetero }\end{array}$ & 18-F-DOPA PET \\
\hline 7 & Varadarajan et al. [16] & 2014 & 15 & Chennai & 4-ABCC8 & Gadolinium scan \\
\hline 8 & Jindal et al. $[17]$ & 2014 & 1 & Delhi & ABCC8/exon 5 & \\
\hline 9 & Dinesh Yadav et al. [18] & 2012 & 1 & Delhi & ABCC8-Intron 31 & Ga-DOTANOC \\
\hline 10 & Seema Thakur et al. [19] & 2011 & 1 & & ABCC8-exon 2,3 & - \\
\hline 11 & Desai et al. [20] & 1997 & 13 & Mumbai & - & - \\
\hline
\end{tabular}

these cases in the last decade. Our case had a heterozygous, paternally inherited ABCC8 mutation missense variant, p.(Gly 111Arg). The only other case with the same ABCC 8 mutation was reported by Jahnavi et al. [15], their case was however homozygous with a diffuse lesion requiring subtotal pancreatectomy and later went on to develop diabetes mellitus.

Vardarajan from Chennai [16] reported four cases of CHI with ABCC 8 mutations, and these one was a paternally derived heterozygous mutation and the Gadolinium scan was suggestive of a diffuse disease. The other two were homozygous.

This case reported by us, however had a focal lesion at the anterior part of the head of pancreas at the junction of the distal body and tail. Both the previous cases of heterozygous $\mathrm{ABCC} 8$ mutation reported by Jahnavi et al and Vardarajan et al had a diffuse pancreatic involvement, one which required subtotal pancreatectomy. This would be the first case to be reported from India with an ABCC8 mutation of heterozygous inheritance with a focal pancreatic lesion.

\section{Management}

The first line of treatment for congenital hyperglycemia is complicated and needs to be carefully titrated to balance the benefits and adverse effects. Diazoxide, a KATP channel agonist, is the mainstay of medical treatment in prolonged hyperinsulinemic hypoglycemia. It inhibits insulin secretion by keeping KATP channels open. It is administered at a dose of $10-20 \mathrm{mg} / \mathrm{kg} /$ day, orally, in three divided doses. Lower doses are required in small for gestation babies [21].

In cases resistant to diazoxide, Octreotide, a somatostatin analogue is used. It causes inhibition of insulin release by activation of somatostatin receptor-5, stabilizing KATP channel and inhibition of calcium mobilization. Lanreotide a long acting release octreotide has been proven to be of benefit in a few articles. It is suggested as a once a month intramuscular dose [22].

However, the treatment for diazoxide resistant and diffuse type mostly require surgery. So, it becomes imperative to have an accurate diagnosis and site of lesions to execute affective treatment. Ultrasound, computed tomography (CT), and magnetic resonance imaging (MRI) are usually non-discriminatory for the purpose of diagnosing and localizing focal CHI.

18-Fluoro-DOPA traces a very specific metabolic pathway and has a very precise biodistribution pattern, making to superior to both the above-mentioned non-invasive techniques and also to pancreatic venous sampling (PVS) and combined selective pancreatic arterial calcium stimulation and hepatic venous sampling (ASVS) [23]. The uptake of amine precursors of 18-F-DOPA is much more pronounced in hyperfunctioning islets, thus making the anatomic delineation much more specific.

Ga-exendin is a new modality that can prove potentially beneficial in detecting pancreatic lesion in PET tracer. It is a glucagon like peptide-1 receptor (GLP-1R) that is expressed on the $\beta$-cell of the pancreas. The endogenous peptide GLP-1 has a very short biological half-life and is very sensitive tool. However, it has been primarily used for diagnosing insulinomas worldwide.

\section{Conclusion}

$\mathrm{CHI}$ is a complicated disease, which requires prompt diagnosis to initiate treatment to prevent irreversible hypoglycemic brain damage. Genetic testing and 18-F-DOPA should be used in conjunction for diagnosis and prognosis.

Once the genetic testing confirms the diagnosis, 18-F-DOPA pinpoints the site of pancreatic lesion; appropriate treatment can be planned for diazoxide responsive and unresponsive cases.

Informed consent has been taken from the parents for publication of this case report.

\section{Funding}

No funding

\section{Acknowledgements}

Dr Chandrasekhar Bal, Department of Nuclear Medicine and PET, All India Institute of Medical Sciences, New Delhi. 
Dr Rajesh Khadgawat, Pediatric and Adolescent Endocrinology Clinic, All India Institute of Medical Sciences

New Delhi.

For genetic testing of the case and parents: University of Exeter Royal, Devon and Exeter NHS Foundation Trust

\section{Conflict of interest}

None

\section{Author contribution}

SR and AS have researched compiled the data and the review. IPS reviewed the whole article and supervised the whole process.

\section{References}

1. Chandran S, Peng FY, Rajadurai VS, Lu YT, Chang KT, et al. (2013) Paternally inherited ABCC8 mutation causing diffuse congenital hyperinsulinism. Endocrinol Diabetes Metab Case Rep. 2013:130041. [Crossref]

2. Mathew PM, Young JM, Abu-Osba YK, Mulhern BD, Hammoudi S, et al. (1988) Persistent neonatal hyperinsulinism. Clin Pediatr (Phila) 27: 148-151. [Crossref]

3. Rahier J, Fält K, Müntefering H, Becker K, Gepts W, et al. (1984) The basic structural lesion of persistent neonatal hypoglycaemia with hyperinsulinism: deficiency of pancreatic D cells or hyperactivity of B cells? Diabetologia 26: 282-289. [Crossref]

4. Leibowitz G, Glaser B, Higazi AA, Salameh M, Cerasi E, et al. (1995) Hyperinsulinemic hypoglycemia of infancy (nesidioblastosis) in clinical remission: high incidence of diabetes mellitus and persistent $\beta$-cell dysfunction at long-term follow-up. $J$ Clin Endocrinol Metab 80:386-392

5. Glaser B, Thornton P, Otonkoski T, Junien C (2000) Genetics of neonatal hyperinsulinism. Arch Dis Child Fetal Neonatal Ed 82: F79-86. [Crossref]

6. Aguilar-Bryan L, Bryan J (1999) Molecular biology of adenosine triphosphatesensitive potassium channels. Endocr Rev 20: 101-135. [Crossref]

7. De León DD, Stanley CA (2007) Mechanisms of Disease: advances in diagnosis and treatment of hyperinsulinism in neonates. Nat Clin Pract Endocrinol Metab 3: 57-68. [Crossref]

8. Hsu BY et al. (2001) Protein-sensitive and fasting hypoglycemia in children with the hyperinsulinism/ hyperammonemia syndrome. J Pediatr 138: 383-389

9. Cuesta-Muñoz AL, Huopio H, Otonkoski T, Gomez-Zumaquero JM, Näntö-Salonen $\mathrm{K}$, et al. (2004) Severe persistent hyperinsulinemic hypoglycemia due to a de novo glucokinase mutation. Diabetes 53: 2164-2168. [Crossref]
10. Molven A, Matre GE, Duran M, Wanders RJ, Rishaug U,et al. (2004) Familial hyperinsulinemic hypoglycemia caused by a defect in the SCHAD enzyme of mitochondrial fatty acid oxidation. Diabetes 53: 221-227. [Crossref]

11. Narayanan E, Kumutha J (2016) Persistent Hyperinsulinism - Hyperinsulinemic Hypoglycemia : Follow up and Review of 16 Cases. Indian journal of applied research. 6:385-87

12. Satayapathi A, Vandana J, Ellard, Flanagan E (2016) Hyperinsulinemic Hypoglycemia of Infancy due to Novel HADH Mutation in Two Siblings. Indian Pediatr. 53:912-913. [Crossref]

13. Gupta RK, Saran RK, Debnath PR, Chadha R (2015) Is histopathology informative for further characterization of DOTANOC-proven islet cell lesions in infancy?. Indian $J$ Pathol Microbiol 58:410-412. [Crossref]

14. Papiya Khawash, Khalid Hussain, Sarah E. Flanagan, Sudip Chatterjee, Basak D (2015) Nifedipine in Congenital Hyperinsulinism- A Case Report. J Clin Res Pediatr Endocrinol. 7: 151-154. [Crossref]

15. Jahnavi S, Poovazhagi V, Kanthimathi S, Balamurugan K, Bodhini D, et al. (2014) Novel ABCC8 (SUR1) Gene Mutations in Asian Indian Children with Congenital Hyperinsulinemic Hypoglycemia. Ann Hum Genet 78: 311-319. [Crossref]

16. Varadarajan P, Ananthanarayanan K, Mirna K, Jahnavi S, Venkatesan R, et al. (2014) Clinical Profile and Outcome of Persistent Hyperinsulinemic Hypoglycemia of Infancy. Pediatric Oncall Journal 11

17. Yadav D, Dhingra B, Kumar S, Kumar V, Dutta AK (2012) Persistent hyperinsulinemic hypoglycemia of infancy. J Pediatr Endocr Met 25:591-593

18. Jindal R, Ahmad A, Siddiqui MA, Kochar IS, Wangnoo SK (2014) Novel mutation c.597_598dup in exon 5 of ABCC8 gene causing congenital hyperinsulinism. Diabetes Metab Syndr. 8:45-47. [Crossref]

19. Thakur S, Flanagan S, Ellard S, Verma IC (2011) Congenital Hyperinsulinism Caused by Mutations in ABCC8 (SUR1) Gene. Indian Pediatrics. 48:733-734. [Crossref]

20. Desai MP, Khatri KV (1998) Persistent hyperinsulinemic hypoglycemia of infancy Indian paediatrics.

21. Tas E, Mahmood B, Garibaldi L, Sperling M (2015) Liver injury may increase the risk of diazoxide toxicity: a case report. Eur J Pediatr 174: 403-406. [Crossref]

22. Modan-Moses D, Koren I, Mazor-Aronovitch K, Pinhas- Hamiel O, Landau H (2011) Treatment of congenital hyperinsulinism with Lanreotide acetate (Somatuline Autogel). J Clin Endocrinol Metab. 96:2312-2317. [Crossref]

23. Blomberg BA, Moghbel MC, Saboury B, Stanley CA, Alavi A (2013) The Value of Radiologic Interventions and 18F-DOPA PET in Diagnosing and Localizing Focal Congenital Hyperinsulinism: Systematic Review and Meta-Analysis. Mol Imaging Biol. 15: 97-105.

Copyright: (C2018 Kochar IS. This is an open-access article distributed under the terms of the Creative Commons Attribution License, which permits unrestricted use, distribution, and reproduction in any medium, provided the original author and source are credited. 